\title{
Some observations regarding non-Newtonian turbulent flow and transition, especially in relation to the Wilson-Thomas (1985) theory
}

\author{
AD Thomas Slurry Systems Pty Ltd, Australia
}

\begin{abstract}
Pipe loop data from Thomas (1978) is compared with trends predicted by the Wilson and Thomas (1985) turbulent flow theory. For a Bingham plastic clay slurry, the theory predicts that as the velocity reduces towards transition, the pressure gradient tends closer towards the water curve. When granular particles, such as sand, are added to the clay slurry, the behaviour changes. Depending on the particle size of the sand and the rheology of the clay slurry, the mixture pressure gradient may trend away from the water curve as the velocity reduces or it may tend to parallel the water curve, or it may trend towards the water line in a similar manner as for clay slurry. These differing behaviours are determined by the size of the sand particles relative to the thickness of the viscous sub-layer. If the sand particles are small enough to reside within the viscous sub-layer they will increase the viscosity within the sub-layer and increase the pressure gradient. Conversely, if the sand particles are too large to reside within the sub-layer, the viscosity is not increased and the pressure gradient is lowered. These $d / \delta$ effects are separate from heterogeneous settling effects which may accentuate the effects.
\end{abstract}

Fitton $(2015,2017)$ has noted a wide range of behaviour for different slurries in the transition region. The $d / \delta$ effects explored in this paper may explain some of these differing behaviours.

Keywords: Bingham plastic, non-Newtonian, turbulent pipe flow, viscous sub-layer

\section{Introduction}

Fitton (2015) has recently reviewed friction factor behaviour in the laminar/turbulent transition region for non-Newtonian slurries. More recently, Fitton (2017), has further discussed this issue and given a method of modelling the friction factor in the transition region. Considering experimental data for both pipe and channel flows, he found a wide range of behaviour for different slurries in the transition region.

With regard to non-Newtonian pipe flow, Wilson and Thomas (1985) presented a new method of predicting turbulent pipe flow for Bingham plastics and power law fluids. The theory was based on thickening of the viscous sub-layer as the velocity reduces towards transition. On a logarithmic plot of pressure gradient versus velocity, the Wilson-Thomas theory predicts a continuous trend of the pressure gradient reducing towards the water line. For an all-colloidal sized Bingham plastic clay slurry, the pressure gradient is predicted to be 10 to $20 \%$ lower than the 'Newtonian' prediction based on the plastic viscosity. This agreed with the generally accepted view at that time (e.g. Bain \& Bonnington 1970; Govier \& Aziz 1972; Wasp et al. 1977) that the turbulent flow pressure gradient of a Bingham plastic was lower than the equivalent Newtonian pressure gradient based on the plastic viscosity, and typically about $15 \%$ lower.

However, most slurries in the mining industry have a wide particle size distribution, with a top size typically up to about 300 to 600 microns, and with only a small percentage of particles colloidal in size. This paper considers the possible effects on the Wilson and Thomas (1985) theory of the wide particle size distribution of typical slurries. Data from pipe loop tests of Thomas (1978) are analysed, but the analysis can be considered to equally apply to open channel flow down deposit slopes. 


\section{Viscosity of suspensions}

Before considering non-Newtonian turbulent flow we need to consider some aspects of laminar flow of suspensions. It is well known that the addition of spheres to a viscous fluid increases the viscosity. An often-used equation is that of Thomas (1965):

$$
\mu_{\mathrm{m}} / \mu_{\mathrm{f}}=1+2.5 \mathrm{Cv}+10.05 \mathrm{Cv}^{2}+0.0273 \exp (16.6 \mathrm{Cv})
$$

where:

$$
\begin{aligned}
& \mu_{\mathrm{m}} \quad=\text { viscosity of mixture (Pa.s). } \\
& \mu_{\mathrm{f}} \quad=\text { viscosity of fluid (Pa.s). } \\
& \mathrm{Cv} \quad=\text { fractional volume concentration of solids. }
\end{aligned}
$$

Landel et al. (1963) presented another equation which included the maximum packing concentration (Cvmax) as a parameter.

$$
\mu_{\mathrm{m}} / \mu_{\mathrm{f}}=\left(1-\mathrm{Cv} / \mathrm{Cv}_{\mathrm{max}}\right)^{-2.5}
$$

The present author (Thomas 1999) found that both Equations 1 and 2 with Cvmax $=0.75$ agreed with his own earlier pipe loop experimental data for sands in high viscosity Newtonian fluids (Thomas 1979), as well as similar data of Shook et al. (1973). Thomas also tested sand in slimes slurries in a rotational viscometer and plotted the plastic viscosity versus $\mathrm{Cv}$ sand. There was a lot more scatter in the data but the data were encompassed by Equation 2 curves with Cvmax $=0.60$ and 0.9 .

More recently, the present author (Thomas 2010) found that Equation 3 closely followed the predictions of Equations 1 and 2 with Cvmax $=0.75$, which is a realistic value for Cvmax for wide size distribution slurries. Figure 1 compares predictions using Equations 1, 2 and 3.

$$
\mu_{\mathrm{m}} / \mu_{\mathrm{f}}=\exp (2.7 \mathrm{Vr})
$$

$\mathrm{Vr}$ is volume ratio, defined as the ratio of volume of solids to the volume of fluid and is given by Equation 4 .

$$
\mathrm{Vr}=\mathrm{Cv} /(1-\mathrm{Cv})
$$

Figure 1 indicates that the Equation 3 curve lies between Equation 2 curves with Cvmax $=0.60$ and 0.9 , so that Equation 3 approximately describes the author's plastic viscosity results for sand in slimes.

It can be noted that Thomas (1999) also conducted rotational viscometer tests on sand in slimes slurries and found that the ratio of yield stress with and without sand addition was described by Equation 2 with $\mathrm{Cvmax}=0.9$. Figure 1 indicates that Equation 3 is in reasonable agreement with Equation 2 with Cvmax $=0.9$ up to $C v$ around 0.3 .

In this current paper, Equation 3 is used for both the viscosity ratio and the yield stress ratio.

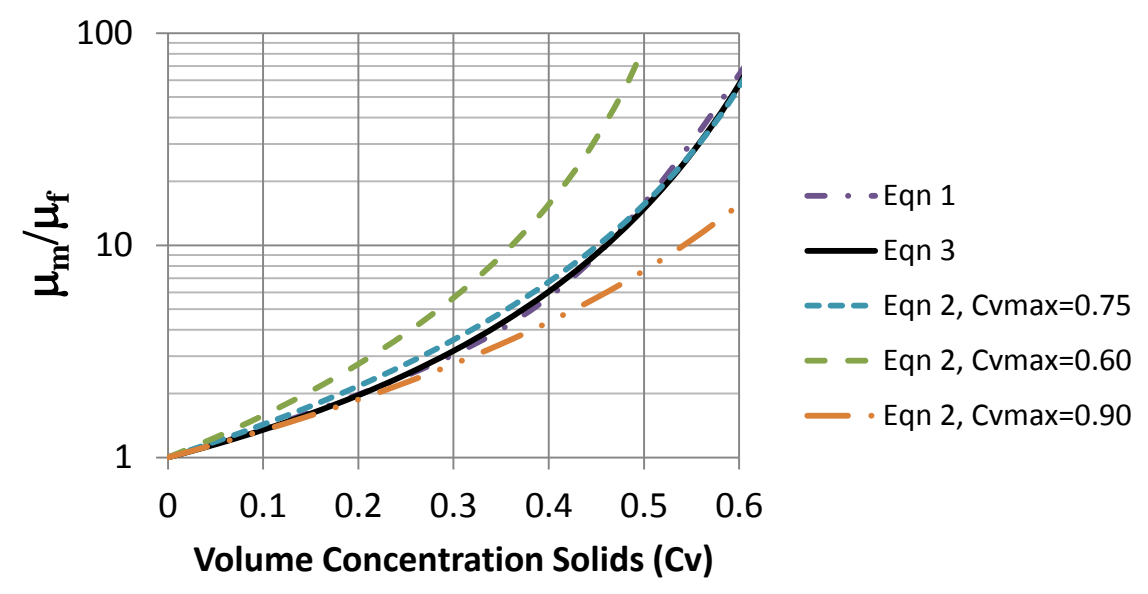

Figure 1 Comparison of Equations 1, 2 and 3 


\section{Particles small enough to fit in sub-layer increase the turbulent pressure gradient}

Thomas (1977) conducted pipe loop tests with sand in water slurries of various sizes, including measuring the pressure gradient at high velocities where heterogeneous settling effects are negligible and flow is pseudo-homogeneous. He found that if the particles are smaller than the thickness of the viscous sub-layer then the pseudo-homogeneous pressure gradient at high velocities was higher than for an equivalent flow of coarse particles.

This effect in sand-water slurries had been recognised by early workers including Durand and Condolios (1952) and Durand (1953). The effect is particularly evident in vertical pipe flow (Durand 1953) and in the horizontal flow of neutrally buoyant particles (Daily \& Roberts 1969).

Thomas (1977) defined the thickness of the viscous sub-layer $(\delta)$ as given by Equation 5 :

$$
\delta=\mathrm{K} \mu_{\mathrm{f}} /\left(\rho_{\mathrm{f}} \mathrm{V}^{*}\right)
$$

where:

$$
\begin{aligned}
\mathrm{K} & =5 . \\
\rho_{\mathrm{f}} & =\text { density of the fluid }\left(\mathrm{kg} / \mathrm{m}^{3}\right) . \\
\mathrm{V}^{*} & =\text { friction velocity }=\mathrm{V}\left(\tau_{\mathrm{w}} / \rho_{\mathrm{f}}\right)(\mathrm{m} / \mathrm{s}) . \\
\tau_{\mathrm{w}} & =\mathrm{DJ} / 4(\mathrm{~Pa}) . \\
\mathrm{J} & =\text { pressure gradient }(\mathrm{Pa} / \mathrm{m}) .
\end{aligned}
$$

Note: The Wilson-Thomas (1985) theory, to be discussed in Section 5, used K = 11.6.

Thomas (1977) tested narrow size distributions sands with $d_{50}$ size $0.13,0.175,0.48$ and $1.2 \mathrm{~mm}$ in 105, 53.8 and $18.9 \mathrm{~mm}$ diameter pipe loops. Thomas also included high velocity data of Schriek et al. (1973) who tested $0.175 \mathrm{~mm}$ sand in 50,100,150, 200, 250 and $300 \mathrm{~mm}$ diameter pipe loops. In the high velocity region where heterogeneous settling effects were negligible, the ratio $J_{2} / J_{w}$ data are as seen in Figure 2 , taken from the 1977 paper. In the nomenclature of that paper $J_{2}$ refers to the slurry pressure gradient in the high test bulk velocity region and $J_{w}$ is the pressure gradient of water alone at the same velocity.

For $d / \delta>10, \mathrm{~J}_{2} / \mathrm{J}_{\mathrm{w}}$ is shown as a constant 1.07 , as suggested by Murphy et al. (1955). The few data points for $\mathrm{d} / \delta>10$ do cluster around 1.07 .

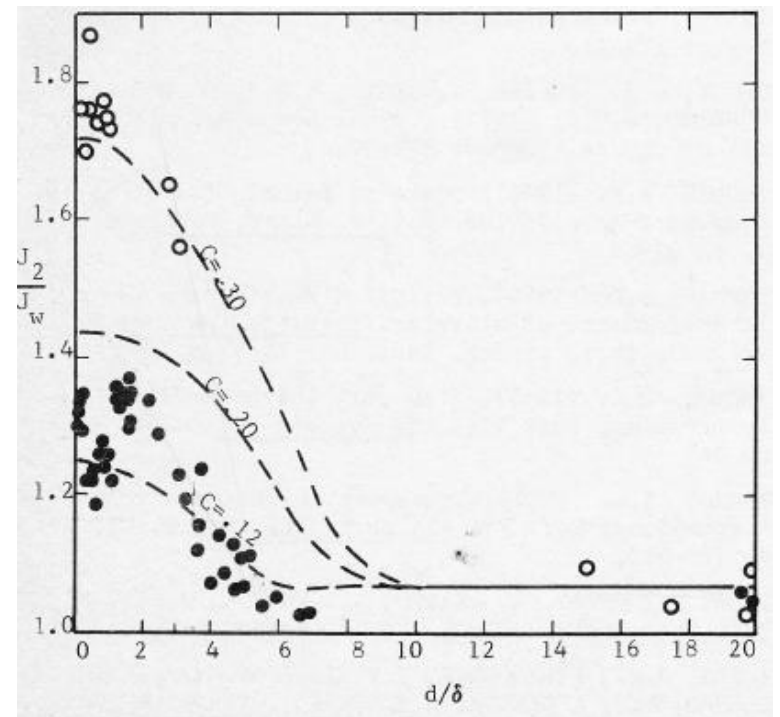

Figure 2 Pressure gradient ratio versus $d / \delta$ (from Thomas 1977). Full data points, $C v=0.12$. Open data points, $\mathrm{Cv}=0.30$ 
Using Equation 3 to predict the slurry viscosity, the predicted turbulent pressure gradients for a velocity of $3 \mathrm{~m} / \mathrm{s}$ in a $105 \mathrm{~mm}$ pipe give a ratio $\mathrm{J}_{2} / \mathrm{J}_{\mathrm{w}}=1.23$ for $\mathrm{Cv}=0.12$ and 1.68 for $\mathrm{Cv}=0.30$. These are reasonably similar to Thomas' (1977) predictions for $\mathrm{d} / \delta=0$ in Figure 2.

With $J_{\mathrm{w}}=655 \mathrm{~Pa} / \mathrm{m}$ at $3 \mathrm{~m} / \mathrm{s}$ in $105 \mathrm{~mm}$ pipe, Equation 5 gives $\delta=0.038 \mathrm{~mm}$ (the $105 \mathrm{~mm}$ ID steel pipe had a hydraulic roughness of $0.0095 \mathrm{~mm}$ due to smoothing from repeated testwork). Since the finest sands tested had a $d_{50}=0.13 \mathrm{~mm}$, Figure 2 suggests that the effective sub-layer thickness at which particles start influencing the viscosity in the sub-layer is perhaps about four times larger than given by Equation 5 with $\mathrm{K}=5$.

It should be noted that the $J_{2} / J_{w}$ ratios in Figure 2 are ratios of pressure gradient, with $J_{2}$ including the effect of the higher slurry density compared with water. If $\mathrm{J}_{2} / \mathrm{J}_{\mathrm{w}}$ is expressed in terms of metres of slurry (water) the ratios are lower. For example at $\mathrm{CV}=0.12$ the predicted $\mathrm{J}_{2} / \mathrm{J}_{\mathrm{w}}$ reduces from 1.23 to 1.03 , and at $\mathrm{Cv}=0.30 \mathrm{~J}_{2} / \mathrm{J}_{\mathrm{w}}$ reduces from 1.68 to 1.13 .

Although not directly relevant to the current investigation, as an aside it is interesting to see the effect that this differing behaviour at high velocities for fine and coarse particles has on the familiar Durand type plots. Thomas' (1977) loop tests relevant to Figure 2 also included tests at lower velocities where heterogeneous settling effects are important.

Figure 3 shows Thomas' (1977) data for coarse, $1.2 \mathrm{~mm}$ sand in three pipe sizes for the full range of velocities in terms of the Durand (1953) parameters $\Phi$ and $\Psi$.

$$
\begin{gathered}
\Phi=\mathrm{K}_{\mathrm{D}} \Psi^{-1.5} \\
\Phi=(J-J \mathrm{w}) /\left(C \mathrm{~V} J_{\mathrm{w}}\right) \\
\Psi=\mathrm{V}^{2} \vee C_{d} /(g D(S-1))
\end{gathered}
$$

where:

$$
\begin{aligned}
\mathrm{K}_{\mathrm{D}} & =\text { Durand parameter. } \\
\mathrm{C}_{\mathrm{d}} & =\text { particle drag co-efficient. } \\
\mathrm{g} & =\text { gravitational constant }(8.81 \mathrm{~m} / \mathrm{s}) . \\
\mathrm{D} & =\text { pipe diameter }(\mathrm{m}) . \\
\mathrm{S} & =\text { solids specific gravity. } \\
\mathrm{V} & =\text { velocity }(\mathrm{m} / \mathrm{s}) . \\
\mathrm{J} & =\text { pressure gradient of slurry }(\mathrm{Pa} / \mathrm{m}) . \\
\mathrm{J}_{\mathrm{W}} & =\text { pressure gradient of water at the same velocity }(\mathrm{Pa} / \mathrm{m}) .
\end{aligned}
$$

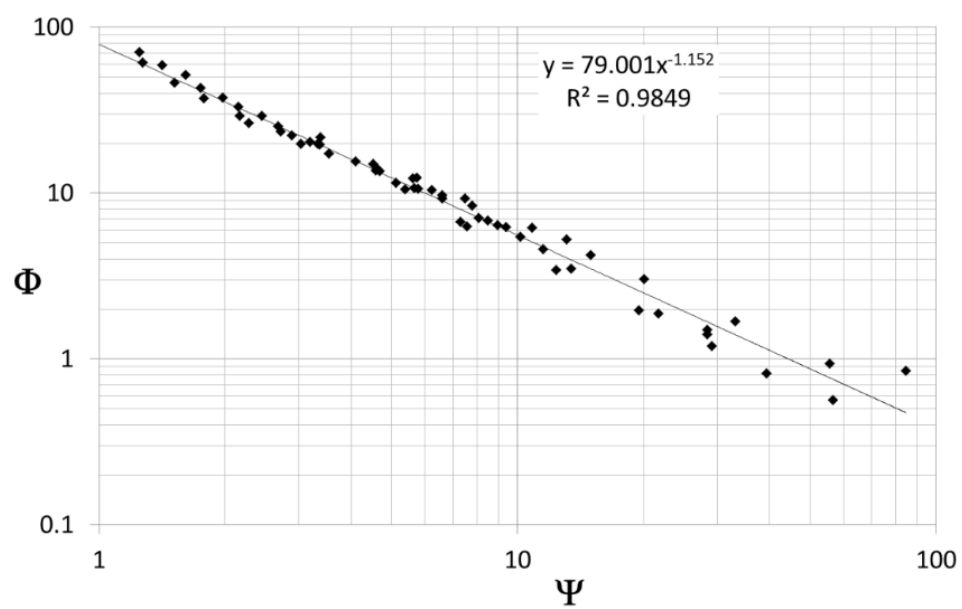

Figure 3 Durand plot for $1.2 \mathrm{~mm}$ sand in $105,53.8$ and $18.9 \mathrm{~mm}$ pipes. $\mathrm{Cv}=0.07$ to 0.24 
The coarse sand $(1.2 \mathrm{~mm})$ data in Figure 3 are well correlated on the Durand plot by the equation indicated. In contrast, Figure 4 shows a similar Durand plot for Thomas' (1977) fine sand $(0.13 \mathrm{~mm})$ data. Compared to Figure 3, there is a wide variation and systematic trends, both with pipe diameter and with $\Psi$ (velocity). In Figure 4, the higher pressure gradients at high velocities caused by the $d / \delta$ effect of Figure 2 causes the Durand parameter $\Phi$ to vary markedly from the Durand prediction. This is a major cause of the scatter evident in Durand plots.

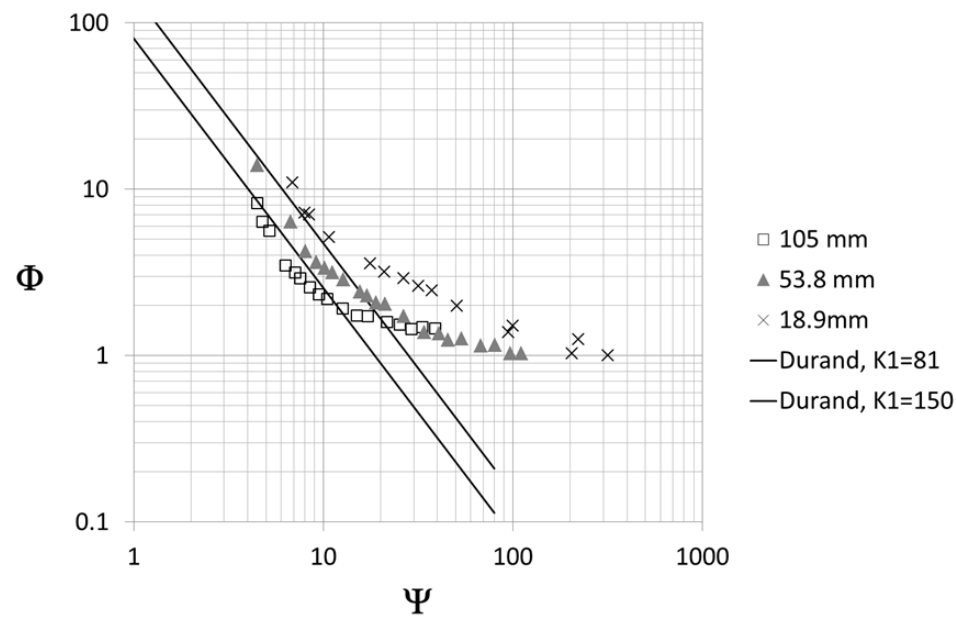

Figure 4 Durand plot for $0.13 \mathrm{~mm}$ sand in $105,53.8$ and $18.9 \mathrm{~mm}$ pipes. $\mathrm{Cv}=0.12$

\section{$4 \quad$ Wilson-Thomas (1985) turbulent flow theory}

\subsection{Wilson-Thomas (1985) theory for smooth pipes}

In 1985, Wilson and Thomas presented a new theory of non-Newtonian flow which was based on thickening of the viscous sub-layer as the velocity reduces towards laminar/turbulent transition. This has the effect of reducing the pressure gradient (or friction factor) as the velocity reduces.

As presented in the 1985 paper:

$$
V / V^{*}=V_{N} / V^{*}+11.6(\alpha-1)-2.5 \operatorname{Ln}(\alpha)-\Omega
$$

where:

$$
\begin{aligned}
& \alpha=1+\tau_{\mathrm{y}} / \tau_{\mathrm{w} .} \\
& \tau_{\mathrm{y}}=\text { Bingham yield stress }(\mathrm{Pa}) .
\end{aligned}
$$

The $\Omega$ term was added to take into account the blunting of the velocity profile due to the yield stress, and is given by:

$$
\Omega=-2.5 \operatorname{Ln}(1-\xi)-2.5 \xi(1+0.5 \xi)
$$

where:

$$
\xi \quad=\tau \mathrm{y} / \tau \mathrm{w} .
$$

Please note that in the 1985 paper the sign in the last bracket of Equation 10 was incorrectly given as a minus sign. This error was noted and corrected in subsequent papers by Wilson and Thomas.

Figure 5 shows one set of Thomas' test data from Thomas (1978) for a 7.39\% by volume kaolin clay slurry in an essentially smooth $105 \mathrm{~mm}$ pipe $(\mathrm{k}=0.009 \mathrm{~mm})$. Bingham yield stress is $6.6 \mathrm{~Pa}$ and plastic viscosity $4.9 \mathrm{mPas}$. The full line curve shows the predicted laminar and turbulent pressure gradients for the clay slurry. Turbulent prediction is as per Wilson and Thomas (Equation 9). The predicted pressure gradient for water is shown by the lower dashed line and the upper dashed line is the Newtonian prediction for the clay slurry based on the plastic viscosity. 


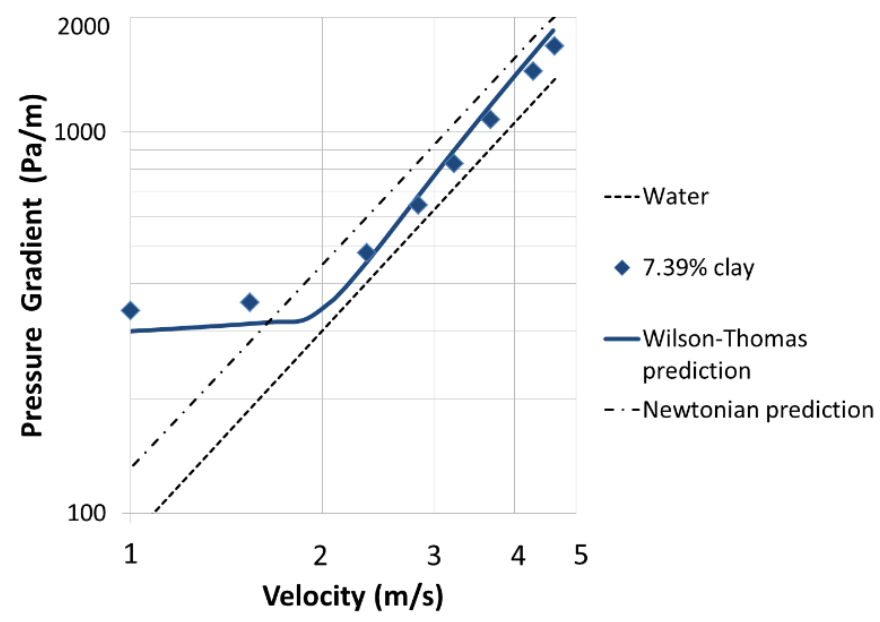

Figure 5 Kaolin clay $(\mathrm{Cv}=7.39 \%)$ in $105 \mathrm{~mm}$ pipe (Thomas 1978)

The Wilson-Thomas turbulent flow curve is $10 \%$ below the Newtonian curve at the highest velocity, reducing to $24 \%$ below the Newtonian curve at $2 \mathrm{~m} / \mathrm{s}$, just before transition. Unfortunately, no data was collected around transition, so no confirmation of predicted transition region behaviour is available in this case.

The thickness of the viscous sub-layer $(\delta)$ is given in the Wilson-Thomas theory by Equation 11 :

$$
\delta=11.6 \alpha \mu_{\text {eff }} /\left(\rho_{\mathrm{f}} \mathrm{V}^{*}\right)
$$

where:

$\mu_{\text {eff }}=\mu_{\mathrm{w}} /(\mathrm{du} / \mathrm{dy})$ and for a Bingham plastic is given by:

$$
\mu_{\text {eff }}=\mu_{\mathrm{pl}} /\left(1-\tau_{\mathrm{y} /} \tau_{\mathrm{w}}\right)
$$

\subsection{Thomas and Wilson (2007) extension to rough wall pipes}

The thickening of the viscous sub-layer is strongly supported by predictions for rough wall pipe data of Slatter and Van Sittert $(1997,1999)$ which were predicted by Thomas and Wilson (2007). Figure 4 of the Thomas and Wilson paper is reproduced as Figure 6. The friction factor, $\mathrm{f}$, is the Stanton-Moody friction factor.

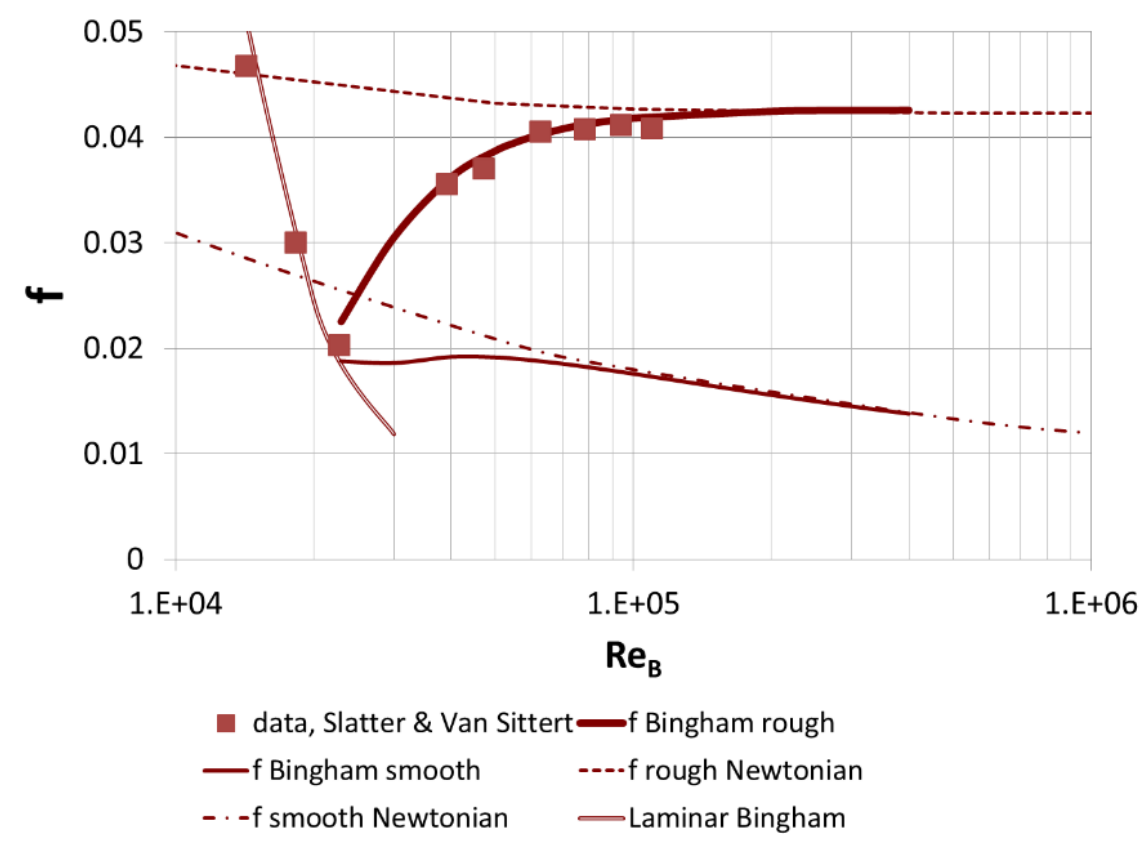

Figure 6 Predicted rough wall friction factor; Thomas and Wilson (2007) compared with data of Slatter and Van Sittert $(1997,1999)$ 
The graph shows data for laminar and turbulent flow of a kaolin clay slurry with yield stress $8.5 \mathrm{~Pa}$ and plastic viscosity $4.4 \mathrm{mPas}$ in a very rough, $45.3 \mathrm{~mm}$ ID pipe of roughness $0.693 \mathrm{~mm}(\mathrm{k} / \mathrm{D}=0.0153)$. There is excellent agreement between the data and predicted turbulent flow friction factor using the rough wall extension of the Wilson-Thomas theory presented in Thomas and Wilson (2007). There is a predicted and observed halving of the friction factor between $\mathrm{Re}_{\mathrm{B}}=1 \mathrm{E} 5$ and $\mathrm{Re}_{\mathrm{B}}=2.3 \mathrm{E} 4$, which is explained by the thickening of the sub-layer which engulfs the roughness within the sub-layer.

The behaviour in Figure 6 applies to a very rough pipe. In pipe flow, such high roughness would be unusual, but could well apply to open channel flow on deposit slopes. Note that the fact that the $0.693 \mathrm{~mm}$ roughness is engulfed within the viscous sub-layer near the transition region would similarly mean that if $0.693 \mathrm{~mm}$ particles were present they could also reside within the sub-layer.

\section{$5 \quad$ Granular particles in non-Newtonian slurries}

\subsection{The $d / \delta$ effect also occurs with non-Newtonian slurries - clay slurry with $0.15 \mathrm{~mm}$ sand}

The discussion concerning $d / \delta$ effects in Section 3 related to fine and coarse sand in water. These $d / \delta$ effects also occur with fine and coarse particles in non-Newtonian slurries. Thomas (1978) discussed the $d / \delta$ effect in detail, with examples of both sand and coal particles in a clay 'vehicle' slurry in the homogeneous flow regime, where heterogeneous effects were negligible, illustrating the higher pressure gradient with fine particles and lower pressure gradient with coarse particles. For example, in a $105 \mathrm{~mm}$ pipe, a kaolin clay slurry with $16.8 \%$ by volume concentration of $0.18 * \mathrm{~mm}$ sand added, exhibited a $7 \%$ higher turbulent pressure gradient at $3.5 \mathrm{~m} / \mathrm{s}$ than with $18.5 \%$ volume concentration of $0.82 \mathrm{~mm}$ sand added.

*Note: Recent examination of the original data reveals that the sand, with $95 \%$ of particles between $0.1 \mathrm{~mm}$ and $0.3 \mathrm{~mm}$, had a $d_{50}$ size of $0.15 \mathrm{~mm}$ rather than the $d_{50}$ of $0.18 \mathrm{~mm}$ as stated in the 1978 paper.

Some of Thomas' loop test results reported in Thomas (1978) for $0.18(0.15) \mathrm{mm}$ sand in a clay slurry in a $105 \mathrm{~mm}$ pipe are compared with Wilson-Thomas (1985) predictions in Figure 7. The clay slurry has a volume concentration of $3.56 \%$, yield stress $1.35 \mathrm{~Pa}$, and plastic viscosity $2.6 \mathrm{mPas}$. Clay slurry density is $1,049 \mathrm{~kg} / \mathrm{m}^{3}$. The volume concentration of sand in the clay slurry is $16 \%$.

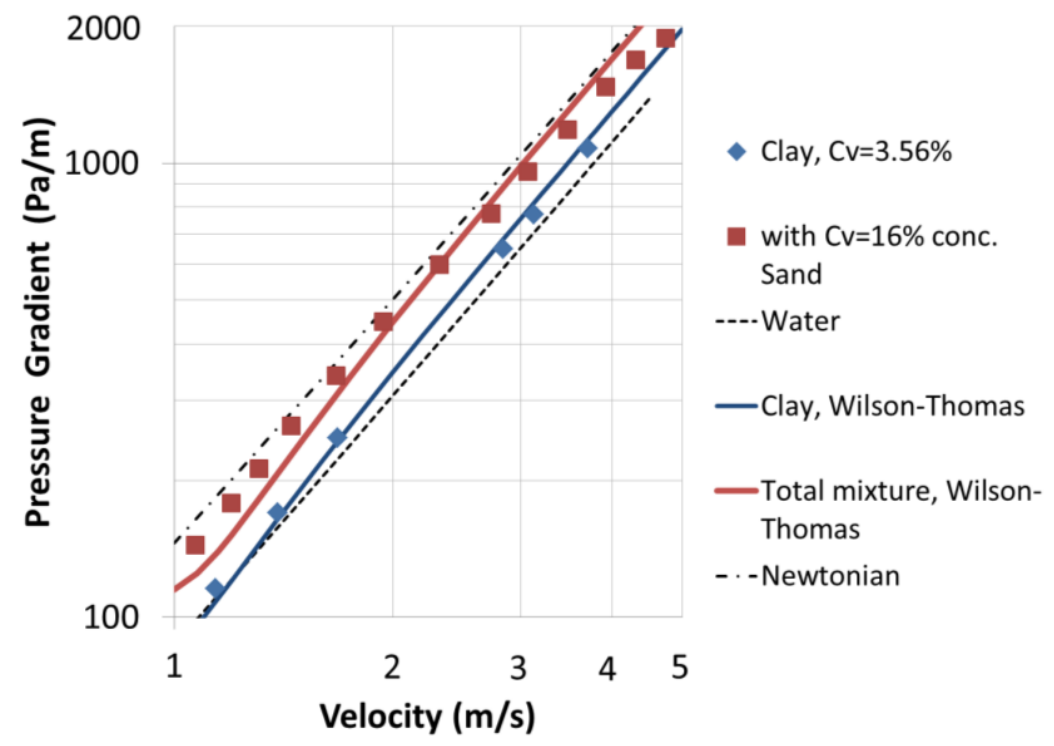

Figure $7 \quad 0.18(0.15) \mathrm{mm}$ sand in $\mathrm{Cv}=3.56 \%$ kaolin clay slurry in $105 \mathrm{~mm}$ pipe

The lower dashed line in Figure 7 represents the pressure gradient of water. The full line above the water line is the Wilson-Thomas turbulent prediction for the clay slurry alone, based on the Bingham parameters given above. The clay data agree reasonably well with the Wilson-Thomas prediction curve. 
To predict the pressure gradient of the sand/clay mixture, the plastic viscosity of the sand/clay mixture has been estimated using Equation 3 as follows: $\mathrm{Cv}$ sand in clay $=0.16$. Therefore, $\mathrm{Vr}=0.19$ and Equation 3 gives a ratio of 1.67. Hence the yield stress of the sand/clay mixture is assumed $1.35 \times 1.67=2.25 \mathrm{~Pa}$ and the plastic viscosity is assumed $2.6 \times 1.67=4.35 \mathrm{mPas}$.

The full line above the clay only curve in Figure 7 is the Wilson-Thomas prediction for the sand/clay mixture based on these estimated Bingham parameters. Transition velocity is about $1.1 \mathrm{~m} / \mathrm{s}$. The uppermost dashed curve in Figure 7 is the Newtonian prediction for the sand/clay mixture based on the mixture plastic viscosity. For this relatively low yield stress slurry, the Wilson-Thomas prediction is only slightly below the Newtonian prediction.

The mixture data points clearly trend towards the clay slurry curve at high velocities. This suggests that as the viscous sub-layer thickness decreases at the higher velocities, a lower proportion of the particles are able to enter the viscous sub-layer and increase the viscosity in the sub-layer. As per the discussion in Section 3, this results in a lower pressure gradient at high velocities. Using Equation 11, the predicted viscous sub-layer thickness $(\delta)$ is $0.14 \mathrm{~mm}$ at $\mathrm{V}=4.75 \mathrm{~m} / \mathrm{s}$ pertaining to the highest mixture data point. Less than half of the sand particles are less than $0.14 \mathrm{~mm}$, suggesting that the majority of the sand cannot reside within the sub-layer. Hence there are fewer particles to increase the viscosity of the sub-layer and so the pressure gradient reduces. This supports the contention that the trending of the mixture data points towards the clay curve at high velocities is associated with the viscous sub-layer $\mathrm{d} / \delta$ effect.

Conversely, at the lower velocities, more of the sand particles are able to enter the sub-layer and increase the viscosity resulting in a higher pressure gradient. For example, at $1.2 \mathrm{~m} / \mathrm{s}$ the calculated sub-layer thickness is $0.8 \mathrm{~mm}$, which is thick enough for all of the sand particles to enter the sub-layer and increase the viscosity and the pressure gradient. A stationary bed was observed at the lowest velocity $(0.86 \mathrm{~m} / \mathrm{s})$ with deposition coinciding with transition at around $1 \mathrm{~m} / \mathrm{s}$.

The overall result is that for this medium-size sand, the $d / \delta$ effect causes the sand/clay mixture pressure gradient to roughly parallel the Newtonian curve for all velocities rather than converging towards the water curve as predicted by the Wilson-Thomas theory and as occurs with the clay slurry.

\subsection{Clay slurry with $0.82 \mathrm{~mm}$ sand}

Thomas (1978) also tested $d_{50}=0.82 \mathrm{~mm}$ sand in the same $C v=7.39 \%$ clay slurry as previously considered in Figure 5. The size distribution of the sand was such that $80 \%$ of the particles were between $0.6 \mathrm{~mm}$ and $1.35 \mathrm{~mm}$. Cv sand in clay slurry $=17.4 \%$. Figure 8 shows the measured pressure gradient of the sand/clay mixture and the current analysis.

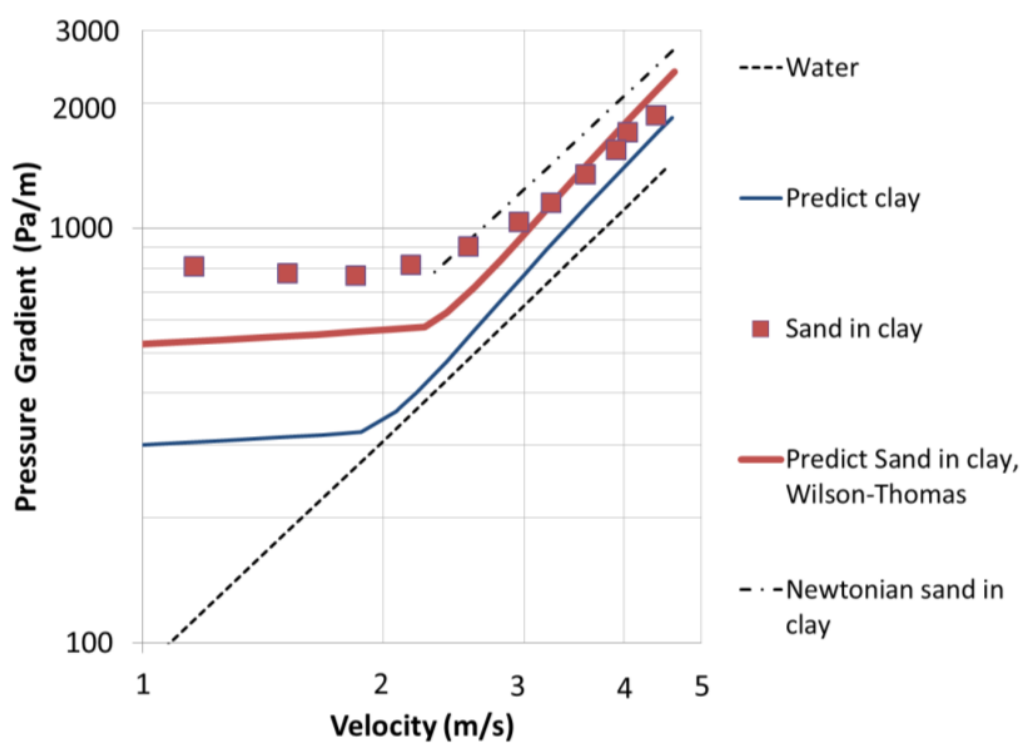

Figure $8 \quad 0.82 \mathrm{~mm}$ sand in $\mathrm{Cv}=7.39 \%$ clay slurry, $105 \mathrm{~mm}$ pipe 
The lower dashed line in Figure 8 represents the pressure gradient of water. The full line above the water line is the Wilson-Thomas turbulent prediction for the clay slurry alone, based on the Bingham parameters relating to Figure 5, with transition to laminar flow predicted at around $1.9 \mathrm{~m} / \mathrm{s}$.

To predict the pressure gradient of the sand/clay mixture, the plastic viscosity of the sand/clay mixture has been estimated using Equation 3 as follows: $\mathrm{Cv}$ sand in clay $=0.174$. Therefore, $\mathrm{Vr}=0.207$ and Equation 3 gives a ratio 1.75 . Hence the yield stress of the mixture is assumed $6.6 \times 1.75=11.5 \mathrm{~Pa}$ and the plastic viscosity is assumed $4.9 \times 1.75=8.57 \mathrm{mPas}$.

The full line above the clay only curve in Figure 8 is the Wilson-Thomas prediction for the sand/clay mixture based on these estimated Bingham parameters. The predicted transition velocity is $2.25 \mathrm{~m} / \mathrm{s}$. The uppermost dashed curve in Figure 8 is the Newtonian prediction for the sand/clay mixture based on the mixture plastic viscosity.

In the turbulent region above $2 \mathrm{~m} / \mathrm{s}$, the mixture data points clearly trend towards the clay slurry curve at high velocities. This suggests that as the viscous sub-layer thickness decreases at the higher velocities, a lower proportion of the particles are able to enter the viscous sub-layer and increase the viscosity in the sub-layer. As per the discussion in Section 3, this results in a lower pressure gradient at high velocities. Using Equation 11 , the predicted viscous sub-layer thickness $(\delta)$ is $0.36 \mathrm{~mm}$, at $V=4.4 \mathrm{~m} / \mathrm{s}$ pertaining to the highest mixture data point. Only $10 \%$ of the sand particles are less than $0.36 \mathrm{~mm}$ suggesting that the majority of the sand cannot reside within the sub-layer at $4.4 \mathrm{~m} / \mathrm{s}$. Hence there are fewer particles to increase the viscosity of the sub-layer and so the pressure gradient reduces. This supports the contention that the trending of the mixture data points towards the clay curve at high velocities is associated with the viscous sub-layer $d / \delta$ effect.

With this relatively coarse $0.82 \mathrm{~mm}$ sand, heterogeneous effects are also important. At the highest velocity data point $(4.4 \mathrm{~m} / \mathrm{s})$ it is predicted that about $13 \%$ of the sand will be flowing heterogeneously rather than fully suspended. This probably explains why the higher velocity data points in Figure 8 are still above the clay curve, even though $90 \%$ of the sand particles are larger than the viscous sub-layer thickness and so should not be contributing to the pressure gradient.

Hence the pressure gradient trend away from the clay curve as the velocity decreases is due to a combination of the $d / \delta$ effect (more particles entering the sub-layer and thereby increasing the pressure gradient), and heterogeneous effects. Note, however, that laminar flow was possible with this sand/clay mixture at velocities below the $2.25 \mathrm{~m} / \mathrm{s}$ transition velocity. Deposition did not occur until $1.16 \mathrm{~m} / \mathrm{s}$.

\subsection{Clay slurry with $8 \times 0.1 \mathrm{~mm}$ coal and $1 \times 0.1 \mathrm{~mm}$ coal}

Thomas (1978) also tested clay slurries with addition of coal particles of two wide size distributions, $(8 \times 0.1 \mathrm{~mm}$ and $1 \times 0.1 \mathrm{~mm})$. These results are not considered in any detail in the current paper other than to say that exactly the same $d / \delta$ effects were found with the coal addition as with the above sand addition. For example, with $20 \%$ by volume addition of coal to clay slurries of volume concentration around $8.5 \%$, in the $105 \mathrm{~mm}$ pipe loop, the pressure gradient with the fine coal at $3 \mathrm{~m} / \mathrm{s}$ was $883 \mathrm{~Pa} / \mathrm{m}$ compared with $657 \mathrm{~Pa} / \mathrm{m}$ with the coarse coal (i.e. with fine coal addition the pressure gradient was $34 \%$ higher than with coarse coal).

\subsection{Effect on friction factor plot}

One of the aims of this paper is to explain some of the observed variations in behaviour around the transition region noted by Fitton $(2015,2017)$. In particular, the current paper has focused on behaviour at velocities one to five times higher than the transition velocity. Much of the variations will simply be due to differences in slurry properties. For a slurry with a low yield stress, the pressure gradient may tend to follow the Newtonian curve down to transition, whereas a slurry with a high yield stress may tend to follow a Wilson-Thomas type prediction, with the pressure gradient curving down towards the water curve as transition is approached. On a friction factor plot, the Wilson-Thomas predicted down slope can extend over a Reynolds number range of five to eight times. This paper has shown how $d / \delta$ effects can also modify the behaviour over this Reynolds number range which may also explain some of the variation observed by Fitton. 
For example, Figure 9 shows the data of Figure 7 plotted as friction factor versus Reynolds number. The Reynolds number is based on the relevant plastic viscosity and density applying to the clay slurry, the sand in clay slurry, or water, whichever the case may be.

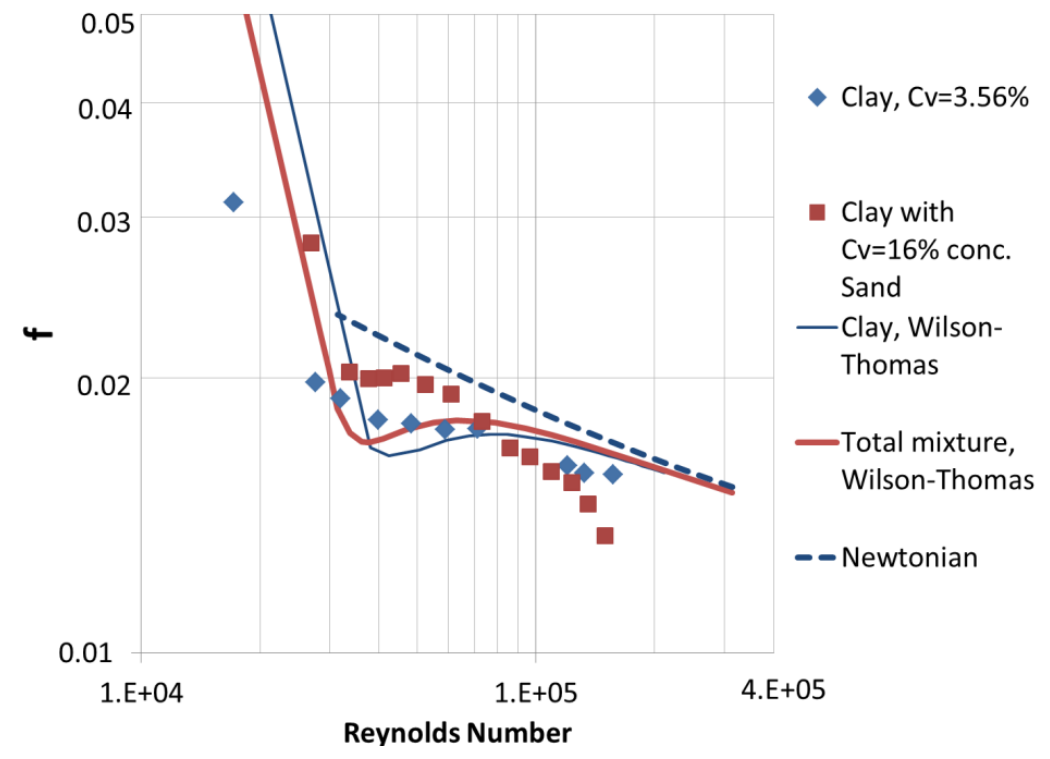

Figure 9 Friction factor plot of $0.18(0.15) \mathrm{mm}$ sand in clay

Firstly, considering the clay only, there is a difference between the Wilson-Thomas prediction for the clay and the clay data. Since the Wilson-Thomas theory is known to predict the behaviour of some slurries, the difference in Figure 9 can be viewed as one of the possible variations in behaviour noted by Fitton.

Addition of non-colloidal size sand to the clay slurry would be expected to make it more Newtonian in behaviour than the clay. Apart from the highest Reynolds number data points, Figure 9 does show the sand/clay mixture friction factor data above the clay and closer to the Newtonian line. However, previous discussion in Section 5.1 has explained how the $d / \delta$ effects reduce the pressure gradient at high velocities, thereby explaining the lowering of the sand/clay mixture friction factor at higher Reynolds numbers.

Figure 9 illustrates the differing behaviour of just two slurries. Mine tailings slurries generally have a wide particle size distribution and can be viewed as comprising coarser 'granular' particles in a non-Newtonian 'vehicle' slurry. Therefore, similar $d / \delta$ effects as discussed here with regard to the 'artificial' mixtures of sand in clay slurries can be expected to also occur with typical mine tailings.

\section{Conclusion}

The Wilson-Thomas (1985) theory for turbulent flow of Bingham plastics predicts a lowering of the pressure gradient towards the water curve as the velocity reduces towards transition. Thomas (1977) tested various narrow size sands in water in three different size test loops. He investigated the differing behaviour when particles are small enough to reside within the viscous sub-layer compared with those that are larger than the sub-layer. Thomas (1978) extended the investigation to non-Newtonian slurries by testing clay slurries with and without the addition of relatively narrow size distribution sands of various sizes and wide size distribution coal particles added.

The current paper has compared the measured pipe loop pressure gradients of Thomas (1978) with predictions based on the Wilson-Thomas (1985) theory. For sand/clay mixtures, Bingham yield stress and plastic viscosity of the clay slurry are increased as a function of the volume concentration of sand added. This increase is quantified as per Thomas (2010).

For any particular sand/clay mixture slurry, as the velocity reduces, the thickness of the viscous sub-layer increases, meaning that a greater proportion of the sand can reside within the sub-layer and increase the 
viscosity within the sub-layer. This results in the pressure gradient of the sand/clay mixture slurry trending further away from the water curve, in contrast to the clay slurry which trends towards the water curve as the velocity decreases. The data of Thomas (1978) show similar $d / \delta$ effects with wide size distribution coal added to the clay slurry, indicating that the same effects will occur with typical wide size distribution tailings.

Fitton $(2015,2017)$ has noted a wide range of behaviour for different slurries in the transition region. A friction factor plot of the $0.15 \mathrm{~mm}$ sand in clay test results (Figure 9 ) has illustrated how the $d / \delta$ effects explored in this paper may explain some of these differing behaviours. In some cases, heterogeneous settling effects, which increase as the velocity reduces, will add to the $d / \delta$ effect.

The loop test data discussed in this paper refers to 'artificial' slurries of sand in clay. Mine tailings slurries generally have a wide particle size distribution and can be viewed as comprising coarser 'granular' particles in a non-Newtonian 'vehicle' slurry. Therefore, similar $d / \delta$ effects as discussed here with regard to the 'artificial' mixtures of sand in clay slurries can also be expected to occur with typical mine tailings. More recent pipe loop data for 'real' slurries in large pipe diameters needs to be considered to investigate this further.

\section{References}

Bain, AG \& Bonnington, ST 1970, The Hydraulic Transport of Solids by Pipeline, Pergamon Press, Oxford.

Daily, WD \& Roberts, PR 1969, 'Rigid particles suspensions in turbulent shear flow', Tappi, vol. 49, no. 3, pp. $115-125$.

Durand, R 1953, 'Basic relationships of the transportation of solids in pipes - experimental research', Proceedings of the 5th Minnesota International Hydraulic Convention, American Society of Civil Engineers, New York, pp. 89-103.

Durand, R \& Condolios, E 1952, 'Experimental investigation of the transport of solids in pipes', Colloquium on Hydraulic Transport, National Coal Board, London.

Fitton, TG 2015, 'A note on non-Newtonian laminar/turbulent transition', in J Sobota and C van Rhee (eds), Proceedings of the 17th International Conference on Transport and Sedimentation of Solid Particles, Delft University of Technology, Delft, pp. 79-86.

Fitton, TG 2017, 'A hydraulic model for predicting the slopes of alluvial deposits', Proceedings of the 20th International Hydrotransport Conference, BHR Group, Cranfield, pp. 239-250.

Govier, GW \& Aziz, K 1972, The Flow of Complex Mixtures in Pipes, Krieger Publishing, Florida.

Landel, RF, Moser, BG \& Bauman, AJ 1963, in EH Lee (ed.), Proceedings of the Fourth International Congress on Rheology: Part 2, John Wiley \& Sons, New York, pp. 663-692.

Murphy, G, Young, DF \& Burian, RJ 1955, Progress Report on Friction Loss of Slurries in Straight Tubes, Report ISC-474, United States Atomic Energy Commission, Germantown.

Schriek, W, Smith, LG, Haas, DB \& Husband, WHW 1973, Experimental Studies on the Transport of Two Different Sands in Water in 2, 4, 6, 8, 10 and 12 Inch Pipelines, Report E73-21, Saskatchewan Research Council, Saskatoon.

Shook, CA, Schriek, W, Smith, LG, Haas, DB \& Husband, WHW 1973, Experimental Studies on the Transport of Sands in Liquids of Varying Properties in 2 and 4 Inch Pipelines, Report E73-20, Saskatchewan Research Council, Saskatoon.

Slatter, PT \& Van Sittert, FP 1997, 'The effect of pipe roughness on non-Newtonian turbulent flow', in J Sobota (ed.), Proceedings of the 9th International Conference on Transport and Sedimentation of Solid Particles, pp. 621-635.

Slatter, PT \& Van Sittert, FP 1999, 'Analysis of rough wall non-Newtonian turbulent pipe flow', Proceedings of the Hydrotransport 14 Conference, BHR Group, Cranfield, pp. 209-222.

Thomas, DG 1965, 'Transport characteristics of suspension: VIII. A note on the viscosity of Newtonian suspensions of uniform spherical particles', Journal of Colloid Science, vol. 20, pp. 267-277.

Thomas, AD 1977, 'Particle size effects in turbulent pipe flow of solid-liquid suspensions', Proceedings of the 6th Australasian Hydraulics and Fluid Mechanics Conference, pp. 113-116.

Thomas, AD 1978, 'Coarse particles in a heavy medium-turbulent pressure drop reduction and deposition under laminar flow', in HS Stephens and L Gittins (eds), Proceedings of the 5th International Conference on Hydraulic Transport of Solids, BHR Group, Cranfield, pp. 63-78.

Thomas, AD 1979, 'Pipelining of coarse coal as a stabilized slurry - another viewpoint', Proceedings of the 4th International Technical Conference on Slurry Transportation, Slurry Transport Association, Washington, DC, pp. 196-205.

Thomas, AD 1999, 'The influence of coarse particles on the rheology of fine particle slurries', Proceedings of Rheology in the Mineral Industry II, United Engineering Foundation Inc, New York, pp. 113-123.

Thomas, AD \& Wilson, KC 2007, 'Rough-wall and turbulent transition analyses for Bingham plastics', Proceedings of the 17th International Conference on the Hydraulic Transport of Solids, BHR Group, Cranfield, and The South African Institute of Mining and Metallurgy, Johannesburg, pp. 76-86.

Thomas, AD 2010, 'Method of determining the inherent viscosity of a slurry and other rheological trends as illustrated by a data bank of over 200 different slurries', Proceedings of the 18th International Conference on Hydrotransport, BHR Group, Cranfield, pp. 325-342.

Wasp, EJ, Kenny, JP \& Gandhi, RL 1977, Solids-liquid Flow Slurry Pipeline Transportation, Trans Tech Publications, Clausthal.

Wilson, KC \& Thomas, AD 1985, 'A new analysis of the turbulent flow of non-Newtonian fluids', The Canadian Journal of Chemical Engineering, vol. 63, pp. 539-545. 

especially in relation to the Wilson-Thomas (1985) theory 